\title{
Conducted Interference
}

National Cancer Institute

\section{Source}

National Cancer Institute. Conducted Interference. NCI Thesaurus. Code C92037.

Problems related to electromagnetic interference (EMI) by physical contact with conductors (e.g. wires, resistors, terminals) as opposed to radiated EMI which is caused by induction (without physical contact of the conductors). 